\title{
Beyond total treatment effects in RCTs: why we need to measure outcomes at baseline when investigating mediation
}

\author{
Sabine Landau1*, Richard Emsley², Graham Dunn² \\ From 3rd International Clinical Trials Methodology Conference \\ Glasgow, UK. 16-17 November 2015
}

\section{Background}

Randomisation in RCTs aims to avoid confounding bias when estimating the average treatment effect (ATE). For continuous outcomes measured post-treatment as well as before randomisation (baseline), analyses based on (i) post-treatment outcome alone, (ii) change scores over the treatment phase and (iii) conditioning on baseline values (ANCOVA), provide unbiased estimators of ATE with ANCOVA known to be most precise. The decision to include baseline values in the analysis is based on precision arguments.

\section{Methods}

Investigators increasingly carry out explanatory analyses to partition total treatment effects into components that are mediated by an intermediate continuous outcome and a non-mediated part. Traditional mediation analysis might be performed based on (i) post-treatment values of the intermediate and clinical outcomes alone, (ii) respective change scores or (iii) conditioning mediator and clinical outcome models on their baseline values. Using MonteCarlo simulation we investigated the performance of these competing estimators.

\section{Results}

Approach (i) will lead to bias in estimates of causal mediation effects when a baseline variable affects both post-treatment variables, and when baseline values of either variable have themselves common causes. The change score approach (ii) can provide unbiased estimates under these confounding scenarios only under additional independence assumptions regarding baseline

${ }^{1}$ King's College London, London, UK

Full list of author information is available at the end of the article levels and change scores, while the conditioning approach (iii) is unbiased.

\section{Conclusions}

Trialists envisaging mediation analyses should measure baseline values of continuous mediators and clinical outcomes. The conditioning approach is recommended to avoid bias in the presence of baseline confounding.

\section{Authors' details \\ 'King's College London, London, UK. ${ }^{2}$ University of Manchester, Manchester, UK.}

Published: 16 November 2015

doi:10.1186/1745-6215-16-S2-042

Cite this article as: Landau et al:: Beyond total treatment effects in RCTs: why we need to measure outcomes at baseline when investigating mediation. Trials 2015 16(Suppl 2):042.

Submit your next manuscript to BioMed Central and take full advantage of:

- Convenient online submission

- Thorough peer review

- No space constraints or color figure charges

- Immediate publication on acceptance

- Inclusion in PubMed, CAS, Scopus and Google Scholar

- Research which is freely available for redistribution

Submit your manuscript at www.biomedcentral.com/submit
() Biomed Central 